\title{
RESULTADOS DE TESTES DE CULTURA E ANTIBIOGRAMA EM SEIS CASOS DE ÚLCERA CORNEANA EM EQUINOS
}

\section{(Culture and antibiogram tests results from six cases of corneal ulcers in horses)}

\author{
FUSCO, M. A. ${ }^{1}$; VIEIRA, J. B. ${ }^{2}$; RAMOS, M. T. ${ }^{3}$; PIRES, N. R. ${ }^{4}$ \\ ${ }^{1}$ Mestre em Clínica Médica e Cirurgia-UFRuralRJ; doutoranda em Cirurgia Geral-UFRJ \\ 2 MV chefe Vetcorr JCB-RJ; mestranda em Clínica e Reprodução Animal - UFF \\ 3 MV JCB-RJ \\ ${ }^{4}$ Professora da UCB
}

\begin{abstract}
RESUMO - A ulceração corneana é uma desordem importante nos olhos eqüinos, podendo levar á cegueira se não tratada adequadamente. Este estudo retrospectivo tem por objetivo mostrar a importância do conhecimento da microbiota comensal de olhos eqüinos, para que, em caso de ulceração corneana, o tratamento seja empregado de forma rápida, enquanto aguardam-se resultados dos testes de cultura e antibiograma para possível ajuste na terapia.
\end{abstract}

Palavras-chave: úlcera corneana; eqüinos; microbiota

\begin{abstract}
Corneal ulcer is an important disorder of the horse eyes, leading to blindness if not treated properly. The objective of this retrospective study is to show the importance of the knowlegde of the comensal microbial flora of horse eyes in order to use a fast and appropriated treatment in case of corneal ulcer. The therapy can be adjusted after the results of culture and antibiogram tests are obtained.
\end{abstract}

Key-words: corneal ulcer; horses; microbial flora 


\section{Resultados de testes de cultura e antibiograma em seis casos de} úlcera corneana em equinos

\section{INTRODUÇÃO}

Nos eqüinos, a ulceração corneana é muito comum pelo fato de apresentarem olhos proeminentes e uma grande superfície corneana, possibilitando a ocorrência de trauma ao epitélio corneano por materiais do solo e de plantas presentes no ambiente em que são mantidos (NASISSE e NELMS, 1992; ANDREW et al., 1998; BROOKS et al., 1998; HAMOR e WHELAN, 1999; BALL, 2000; MICHAU et al., 2003; BROOKS, 2005). O defeito no epitélio corneano permite a aderência de bactérias e fungos residentes do olho normal, ou patogênicos (MATTHEWS, 1994; MOORE et al., 1995; HAMOR E WHELAN, 1999; ANDREW et al., 2003; BROOKS, 2005). A conjuntiva, margem palpebral e sistema de drenagem nasolacrimal de olhos eqüinos saudáveis apresentam predominantemente bactérias aeróbias gram-positivas como Staphylococcus, Streptococcus, Corynebacterium, Bacillus e Streptomyces spp. (NASISSE e NELMS,1992; HAMOR e WHELAN, 1999; ANDREW et al., 2003; GEMENSKY-METZLER et al., 2005). As bactérias gram-negativas são bastante incomuns, mas já foram isoladas Neisseria, Moraxella, Enterobacter, Acinetobacter spp e Escherichia coli (NASISSE e NELMS, 1992; MOORE et al., 1995; ANDREW et al., 2003; GEMENSKY-METZLER et al., 2005). Bactérias anaeróbias nunca foram isoladas (MULLER e WOUK, 2006). Os isolados fúngicos variam com a localização geográfica e manejo do animal (NASISSE e NELMS, 1992; ANDREW et al., 1998; ANDREW et al., 2003), sendo os mais comumente isolados, Aspergillus, Penicillium, Alternaria, Cladosporium e Fusarium spp. (NASISSE e NELMS, 1992; HAMOR e WHELAN, 1999; ROSA et al., 2003; GEMENSKY-METZLER et al., 2005). Na ulceração corneana, a microbiota pode tornar-se predominantemente gram-negativa (MOORE et al., 1995; MULLER e WOUK, 2006), sendo mais encontradas Pseudomonas aeruginosa, Escherichia coli, Acinetobacter, Enterobacter, Klebsiella e Proteus spp. (NASISSE e NELMS, 1992; MULLER e WOUK, 2006). As bactérias grampositivas comumente responsáveis pela infecção corneana são Streptococcus e Staphylococcus spp. (NASISSE e NELMS, 1992; SAUER et al., 2003; MULLER e WOUK, 2006). Apesar de serem comumente implicados na infecção da ulceração corneana, os fungos são os organismos menos observados (BROOKS et al., 1998), encontrandose entres estes o Aspergillus (NASISSE e NELMS, 1992). A infecção corneana tanto por bactérias quanto por fungos pode acontecer (HAMOR e WHELAN, 1999), apesar de serem mutuamente inibitórios os produtos de metabolismo de bactérias e fungos (NASISSE e NELMS, 1992). Quando o processo ulcerativo perdura por mais de 7-10 dias, ou quando a úlcera apresenta rápida progressão, devem-se realizar exames de citologia, cultura e antibiograma para estabelecimento da causa da infecção (bacteriana e/ou fúngica) e direcionamento do tratamento (NASISSE e NELMS, 1992; SAUER et al., 2003). As amostras para realização de cultura devem ser obtidas antes do uso do corante de fluoresceína ou anestésico tópico, pois estes podem inibir o crescimento de microorganismos (HAMOR e WHELAN, 1999). Amostras devem ser obtidas nas bordas da ulcera quando há suspeita de contaminação bacteriana, ou do centro da lesão, quando há suspeita de contaminação fúngica (HAMOR e WHELAN, 1999). O raspado corneano para realização de citologia é realizado com o uso de anestésico tópico (BISTNER e RIIS, 1979). A ulceração corneana pode resultar em necrose progressiva, ulceração estromal profunda, fibrose estromal, ruptura do olho com formação de estafiloma, endoftalmite e phithsis bulbi acarretando a cegueira (MATTHEWS, 1994; MOORE et al., 1995). Por isso há necessidade de tratamento agressivo imediato, logo após a obtenção das amostras, baseado nos resultados da citologia e no conhecimento dos organismos mais comumente isolados (HAMOR e WHELAN. 1999; MOORE et al., 1995), mesmo nos casos mais simples (HAMOR e WHELAN, 1999; MICHAU et al., 2003; BROOKS, 2005), enquanto aguardam-se os resultados dos exames de cultura e antibiograma. Além disto, há necessidade do controle da inflamação intraocular secundária (por reflexo antidrômico) e das complicações subseqüentes a este evento fazendo-se uso de antiinflamatórios não-esteroidais por via sistêmica e/ou tópica e cicloplégico tópico (HAMOR e WHELAN, 1999).

\section{MATERIAL E MÉTODOS}

Durante o período compreendido entre fevereiro de 2000 e outubro de 2004, foram atendidos no Hospital Veterinário Octávio Dupont do Jockey Club Brasileiro-RJ, seis eqüinos PSI, (duas fêmeas e seis machos, idade média quatro anos) portadores de úlcera corneana sem evolução satisfatória mesmo após 20 dias de tratamento prévio com pomada oftálmica à base do antibiótico cloranfenicol e creme vaginal à base do antifúngico nistatina aplicado no fórnix conjuntival do olho portador da ceratite ulcerativa. A conduta terapêutica então se voltou para a pesquisa laboratorial do agente infeccioso perpetuante da ulceração, uma vez que ao exame oftálmico foi descartada qualquer outra causa 
de injúria à córnea, como cílios ectópicos, corpos estranhos ou neoplasias de pálpebra. Realizou-se então coleta através de swab estéril de amostra da área corneana ulcerada para realização de cultura e antibiograma.

\section{RESULTADOS}

Em todos os casos (100\%) houve crescimento de Staphylococcus aureus. Em dois casos (33,3\%) houve crescimento concomitante de Pseudomonas spp. O tratamento então foi baseado nos testes de sensibilidade ao antibiograma, sendo selecionados antibióticos tópicos oculares à base de eritromicina a $1 \%$ nos casos em que o Staphylococcus aureus foi isolado unicamente, e ciprofloxacina a $0.5 \%$ nos casos em que foram isolados Staphylococcus aureus e Pseudomonas spp. Os colírios antibióticos foram formulados em farmácia de manipulação. Os antibióticos eram aplicados a cada duas horas. Somado ao antibiótico, fez-se o uso do colírio de atropina a $1 \%$, uma gota até alcance de midríase e uma gota por dia para manutenção. Devido a dor associada à ceratite ulcerativa bem como a forte musculatura orbicular do eqüino, o tratamento tópico torna-se de difícil aplicação; portanto fez-se o uso do sistema de lavagem subpalpebral (HAMOR e WHELAN, 1999). A melhora significativa do quadro ulcerativo após cinco dias de tratamento fez com que houvesse a manutenção da terapia antibiótica até remissão total da úlcera, observada através do resultado negativo do teste com fluoresceína.

\section{DISCUSSÃO}

A infecção da ulceração corneana por bactérias é bastante observada nos eqüinos (KELLER e HENDRIX, 2005). O uso de forma profilática de antibióticos em ulceração corneana está relacionado à sua infecção (HAMOR e WHELAN, 1999; BALL, 2000). Sabe-se que o uso crônico de antibióticos pode inibir o crescimento de bactérias comensais e alterar a flora conjuntival tornando-a essencialmente gram-negativa, gerando o crescimento exacerbado de um microorganismo oportunista e induzindo ao fenômeno de resistência antimicrobiana (NASISSE e NELMS, 1992; MATTHEWS, 1994; MOORE et al., 1995; HAMOR e WHELAN,1999). Entretanto, a freqüência da bactéria gram-negativa Pseudomonas spp foi menor em relação à bactéria gram-positiva Staphylococcus aureus, contrariando as afirmações de que estes são os microorganismos mais comumente isolados de úlceras corneanas em eqüinos (NASISSE e NELMS, 1992; MOORE et al., 1995;
MULLER e WOUK, 2006). Após o conhecimento dos resultados dos testes de cultura e antibiograma, o quadro clínico apresentou melhora com a escoIha do antibiótico mais apropriado para a infecção presente. A úlcera deve ser avaliada diariamente para possíveis ajustes na terapia. Tanto em úlceras bacterianas quanto fúngicas, a não progressão da úlcera é o primeiro sinal de melhora do quadro (NASISSE e NELMS, 1992). A cultura fúngica não foi realizada, mas a melhora clínica com o tratamento antibacteriano nos leva a crer que a infecção corneal mista não ocorreu em nenhum animal deste estudo retrospectivo, talvez pelo uso prévio de antifúngico, ou então confirmando a ação inibitória de bactérias sobre o crescimento fúngico (NASISSE e NELMS, 1992).

\section{CONCLUSÃO}

Nos casos de úlcera corneana de rápida progressão, que não respondem ao tratamento à base de antibiótico de largo espectro, o conhecimento do microorganismo através da citologia e do isolamento do mesmo em cultura além da susceptibilidade do agente infeccioso através da realização do antibiograma se tornam particularmente importantes. Nos animais deste estudo retrospectivo não foi realizada a citologia, mas após realização da revisão de literatura, os autores entenderam a importância deste exame para avaliação da presença de bactérias e/ou fungos. Assim o profissional pode rapidamente decidir sobre a terapia a ser empregada imediatamente e de forma agressiva até a obtenção do resultado da cultura e do antibiograma. De posse destes resultados, o tratamento prévio pode ser mantido ou alterado, no intuito de recuperar a córnea e até mesmo o globo ocular, e a visão do animal.

\section{REFERÊNCIAS}

ANDREW, S.E.; BROOKS, D.E.; SMITH, P.J.; GELATT, K. N.; CHMIELEWSKI, N.T.; WHITTAKER, C.J.G. Equine Ulcerative Keratomycosis: visual outcome and ocular survival in 39 cases (1987-1996). Equine Veterinary Journal, v.30, p.109-116, 1998.

ANDREW, S.E.; NGUYEN, A.; JONES, G.L.; BROOKS, D. E. Seasonal effects on the aerobic bacterial and fungal conjunctival flora of normal thoroughbred brood mares in Florida. Veterinary Ophthalmology, v.6, p. 45-50, 2003.

BALL, M.A. Equine Fungal Keratitis. Compendium 
Resultados de testes de cultura e antibiograma em seis casos de úlcera corneana em equinos

On Continuing Education for the Practicing Veterinarian, v.22, p.182-186, 2000.

BISTNER, S.I.; RIIS, R.C. Clinical aspects of mycotic keratitis in the horse. Cornell Veterinarian, v.69, p.364-74, 1979.

BROOKS, D.E. Ulceração Corneana. In: Brooks D. E. Oftalmologia para Veterinários de Eqüinos, $1^{\circ} \mathrm{ed}$. São Paulo: Editora Roca, 2005, p.55-83.

BROOKS, D.E.; ANDREW, S.E.; DILLAVOU, C. L.; ELLIS, G.; KUBILIS, P.S. Antimicrobial susceptibility patterns of fungi isolated from horses with ulcerative keratomycosis. American Journal of Veterinary Research, v. 59, p.138-142, 1998.

GEMENSKY-METZLER, A.J.; WILKIE, D.A.; KOWALSKI, J.J.; SCHMALL, L.M.; WILLIS, A.M.; YAMAGATA, $M$. Changes in bacterial and fungal ocular flora of clinically normal horses following experimental application of topical antimicrobial or antimicrobial-corticosteroid ophthalmic preparations. American Journal of Veterinary Research, v.66, p.800-11, 2005.

HAMOR, R.E.; WHELAN N.C. Equine infectious keratitis. Veterinary Clinics of North America:Equine Practice, v.15, p.623-646,1999.

KELLER, R. L.; HENDRIX, D. V. Bacterial Isolates and Antimicrobial Susceptibilities in Equine Bacterial Ulcerative Keratitis (1993-2004). Equine veterinary Journal, v.37, p.207-11, 2005.

MATTHEWS, A.G. The aetiopathogenesis of infectious keratitis in the horse. Equine Veterinary Journal, v.26, p.432-433, 1994.

MICHAU, T.M.; SCHWABENTON, B.; DAVIDSON, M.G.; GILGER, B.C. Superficial, nonhealing corneal ulcers in horses: 23 cases (1989-2003). Veterinary Ophthalmology, v.6, p.291-297, 2003.

MOORE, C.P.; COLLINS, K. B.; FALES, W.H. Antibacterial susceptibility patterns for microbial isolates associated with infectious keratitis in horses: 63 cases (1986-1994). Journal of the American Veterinary Medical Association, v.207, p.928-933, 1995.

MULLER, G.; WOUK, A.F.P.F. Ceratite Ulcerativa por Pseudomonas aeruginosa no cavalo - Revisão. Revista do Conselho Federal de Medicina Veterinária, v.37, p.38-48, 2006.
NASISSE, M.P.; NELMS, S. Equine ulcerative keratitis. Veterinary Clinics of North America:Equine Practice, v.8, p.537-555, 1992.

ROSA, M.; CARDOZO, L. M.; PEREIRA, J.P.; BROOKS, D.E.; MARTINS, A.L.B.; FLORIDO, P.S.S.; STUSSI, J.S.P. Fungal flora of normal eyes of healthy horses from the state of Rio de Janeiro, Brazil. Veterinary Ophthalmology, v.6, p.51-55, 2003.

SAUER, P.; ANDREW, S.E.; LASSALINE, M.; GELATT, K.N.; DENIS, H. M. Changes in antibiotic resistance in equine bacterial ulcerative keratitis (1991-2000): 65 horses. Veterinary Ophthalmology, v.6, p.309-313, 2003.

Recebido para publicação:

$07 / 03 / 2007$

Aprovado: 